\title{
Practice for Cultivating Top-level Postgraduates of Agriculture Relied on Collaborative Innovation Platform
}

\author{
Wenxin JIN, Shuangshuang LI, Xiong LI, Yunyun ZHOU, Yihong HU, Xuejiao ZHANG, Xiansheng TAN, Taoli \\ LIU, Xiu LIU, Chenzhong JIN* \\ Hunan Provincial Collaborative Innovation Center for Field Weeds Control Hunan University of Humanities, Science and \\ Technology Loudi, 417000, China \\ *Corresponding author, e-mail: 532479626@qq.com
}

\begin{abstract}
On the basis of building an on-campus and off-campus high-level collaborative innovation platform, Hunan University of Humanities, Science and Technology organized an on-campus and off-campus dual-tutor team, explored the united cultivation of applied postgraduates in agriculture with enterprise and public institution, which enhanced the adaptability of services for local social and economic development of our college, and promoted the service ability and level. Thus, there was a marked improvement in cultivation quality of postgraduates.
\end{abstract}

Keywords—collaborative innovation; platform; base; postgraduate; cultivation

\section{INTRODUCTION}

Hunan University of Humanities, Science and Technology comprehensively implements the National Medium- and Long-Term Plan for Education and regards the improvement of cultivation quality of postgraduates in agriculture as the most important and pressing task in reform and development of postgraduates education [1]. From 2012 to 2016, we chose postgraduates in agriculture from plant protection field as a pilot. With the help of innovation in systems and mechanisms, we set up some collaborative innovation platform and transformed "high quality resources" to provide services for cultivation of postgraduates in agriculture. We also deepened the cooperation with enterprises and public institutions to achieve united cultivation of postgraduates from plant protection field, which has further strengthened the adaptability of services for local social and economic development of higher education, and upgraded the quality of postgraduates cultivation in plant protection field [2].

\section{CREATE HIGH-LEVEL “COLLABORATIVE INNOVATION” PLATFORM ON THE BASIS OF MECHANISM INNOVATION AND A HUGE POOL OF ADVANTAGES}

\section{A. Build a high-level on-campus platform for practical innovation}

Since 2012, our university has accumulatively invested about four million yuan to build the collaborative innovation platform, including the overall design, structural adjustment and layout optimization of traditional laboratories, so as to explore the mechanisms and modes for talents cultivation, scientific research, disciplinary development and integrated construction of laboratories. Based on the advantage of close relationship with enterprises and public institutions and the mode of on-campus laboratories and innovation platform created by our university and enterprises, the advanced technical equipment of enterprises and research institutes can be matched with postgraduates' practical teaching, which stimulates the forming of series of practical platforms with industry characteristics for postgraduates. Some provincial innovation and experiment platforms, such as Hunan Provincial Collaborative Innovation Center for Field Weeds Control, Key Laboratory of Harmless Application of Pesticide in Hunan Higher Education, Hunan Provincial Experiment Demonstration Center for Agricultural Biotechnology, Hunan Provincial Experiment Center for Virtual and Simulative Teaching of Modern Agriculture and Bioengineering, are cooperatively established by Hunan University of Humanities, Science and Technology and some enterprises and institutions, including Hunan Zhennong Co. Ltd. of Science \&Technology, Hunan Haili Hi-tech Industrial Group, Hunan Wan Jiafeng Co. Ltd. of Science and Technology, Hunan Provincial Research Center for Agricultural Biotechnology, Hunan Academy of Agricultural Sciences and Hunan Provincial Plant Protection Station. Depending on scientific research tasks of industrial practice cooperated by professors and enterprise experts, we have developed 12 experimental teaching softwares, created and designed a batch of innovative experiment projects. A special fund of 1.6 million yuan has invested to the newly-built and on-campus intelligent greenhouse which is of a total area of $1536 \mathrm{~m}^{2}$ and managed by our university. It is a base for agricultural science research and innovative practice activities, guaranteeing the site and environment for postgraduates to conduct on-campus professional practice, implement innovation and research projects and innovative business plans. 


\section{B. Establish a top-level off-campus base for the untied cultivation of talents}

In recent years, relying on pesticide sciences of Hunan provincial key discipline and innovative platforms and teams, such as Key Laboratory of Harmless Application of Pesticide in Hunan Higher Education, we has established a mutually beneficial and win-win cooperative platform for postgraduates' cultivation on the basis of long-term cooperation with enterprises and public institutions. Since 2014, our university has invested a special fund of 1.3 million yuan to support our postgraduates' internship and practice in co-cultivation units, the argumentation and formulation of training programs and the construction of dual-tutor team (including those who are not tutors but provide practical guidance). Among them, the cultivation base co-established by Hunan Haili Hi-tech Industrial Group (Hunan Research Institute of Chemical Industry) has become Hunan provincial demonstration base for postgraduates' cultivation. We have perfected the on-campus and off-campus professional practice guidance document, management document and operating procedures for postgraduates, established management regulations for the demonstration base constructed the team of intramural and extramural academic advisors and have recruited more than 30 full-time and part-time teachers from relevant industries and enterprises to set up a practical guidance team combined by our university, local education government and enterprises.

\section{Initiate a high-level scientific "collaborative innovation" platform}

Integrating with national demands for modern agriculture development, aiming at frontiers of industry and technology, fully utilizing the existed resources of our university and deeply cooperating with scientific institutions, enterprises and local government, we explored and established the "collaborative innovation" mode with various forms which is appropriate for different research tasks. After years of unremitting efforts, we have broken through several key technologies in plant protection field, forming the cultivation chain related with industry-university-research cooperation, fundamental research, technology research and development, laboratory simulation, on-site operation, laboratory scale, pilot scale test, demonstration and extension, productization and industrialization. Then, three relatively-independent collaborative innovation platforms, integrated with talents cultivation and solutions for vital issues, have been set up. One is Hunan Provincial Collaborative Innovation Center for Field weeds control, a research and innovation platform for the implementation of relevant theories and technical cooperation. Focusing on national significant fundamental researches, strategic high-tech researches among industries, major technological plans and the national major engineering projects, it aims at food safety of national strategic demands and frontiers of industrial technology, and integrates scientific teams and resources. The second is the collaborative platform for scientific achievements transformation, which promptly makes its transformation of scientific achievements from our advisors to consolidate the productivity of Hunan Zhennong Co. Ltd. of Science \& Technology; the third is the collaborative platform for industry research and development, which is intended to make science and technology resources open to industries, enterprises and the society, promote resource sharing between our college and the society, and improve service abilities for economic and social development of Key Laboratory of Harmless Application of Pesticide in Hunan Higher Education.

\section{INTENSIFY REFORMATION, DEEPEN COOPERATION AND RELY ON CREATIVE PLATFORM TO CULTIVATE APPLIED TALENTS}

\section{A. Relied on the on-campus and off-campus platform for practical innovation, and conduct the basic training of scientific research innovation and service requirement abilities}

Inside our university, thanks to integrated resources and complete systems, multiple modes of field elective courses, innovative experiment programs for postgraduates, graduation design and postgraduates' participation in scientific research are established, which make high-level scientific research platforms, such as the major laboratories affiliated to a province or ministry and the collaborative innovation center, be available for postgraduates. Since 2012, eleven innovation programs at the university and provincial levels, instructed by tutors or established by postgraduates on their own, have successfully come into conclusions. Besides, more than 20 programs are being conducted. Relying on these platforms, innovation abilities of postgraduates are promoted continuously.

\section{B. Relied on high-level and popular united cultivation base, cultivate top-level applied postgraduates}

Keeping a firm grasp on teaching reform projects at the university and the provincial levels, we made efforts to explore the modes and methods for united cultivation of postgraduates with off-campus enterprises. To begin with, we held serial thematic seminars, worked out guidance document and constructive document for united cultivation and definitely put forward our tasks. What's more, cultivating plans were cooperatively made by relevant enterprises and our university, the main curriculum system was developed with a combination of theory and practice, and the syllabus for theory and practice courses was perfected. The cultivation of professional quality, practical ability and technology extension ability in plant protection should be highlighted. Most importantly, postgraduates were selected by both intramural and extramural academic advisors and "three duals, four modules and seven phases" mode was explored to cultivate postgraduates in plant protection field. We not only set up a guiding committee constituted by local government, enterprises and our university, but also shared the responsibility of postgraduates cultivation with enterprises instead of colleges or universities' domination, which gave access to employers to get involved in talents cultivation and select their potential employees. As an important exploration in reform experimental units, its effect was remarkable. By the end of 2016, the former three terms of postgraduates in plant protection field had been all employed by relevant enterprises and institutions. 
Among them, Deng Yanan and Kong Xuanqing have worked in Hunan Academy of Agricultural Sciences and Hunan Research Institute of Chemical Industry, respectively.

With the deep development of each task in the platform of Hunan Provincial Collaborative Innovation Center for Field weeds control, to cultivate postgraduates, Hunan University of Humanities, Science and Technology (especially the plant protection field) has been actively exploring the collaborative innovation among our university, enterprises and institutions since 2014 . When it comes to academic dissertations, $80 \%$ of our postgraduates have finished them by learning subject research from their advisors and the research tasks of core technology in scientific programs collaborated by industrial enterprises, scientific institutions, production lines and our university. These academic dissertations not only possessed abundant real evidences, scope and multidisciplinary explorations, but also integrated theory and practice. Topics were always "to the point" accordingly. Meanwhile, social and economic benefits were obvious, and the cultivating level and service ability of our postgraduates were comprehensively enhanced.

\section{ACKNOWLEDGMENT}

This program was supported by Innovation Base for Postgraduates Cultivation of Hunan Province (2261602) and Research Project of Teaching Reform of Degree and Graduate Education in Hunan (JG2016B106).

\section{REFERENCES}

[1] X. Li, W. Lu, and X. Hao, "The mechanism construction of university-enterprise cooperative education," Journal of Shenyang Jianzhu University (Social Science), vol.19, pp.205-209, 2017

[2] X. Lin, "On the path of strengthening collaborative innovation in colleges and universities", Journal of Liupanshui Normal University, vol.29, pp.74-76, 2017 